\title{
Efficacy of different estrus synchronization protocols on estrus induction response and conception rate in acyclic and cyclic crossbred cows
}

\author{
AR Prajapati, AJ Dhami, KK Hadiya, JA Patel and JP Prajapati
}

Received: 02 September 2018 / Accepted: 01 January 2019 / Published online: 18 April 2019

(C) Indian Dairy Association (India) 2019

\begin{abstract}
A study was carried out under field conditions on 50 acyclic/anestrus and 50 cyclic/ repeat breeder HF crossbred cows to evaluate the efficacy of four standard estrus induction/ ovulation synchronization protocols, viz., Ov_synch (GPG), Ov_synch Plus (PMSG+GPG), Double_synch (P-GPG) and Estradoublesynch (P-GPE) (10 cows in each protocol, and in untreated controls) in terms of estrus induction response and conception rates at induced estrus with fixed time AI (FTAI) and overall of 3 cycles. All the selected animals received presynchronization treatment, viz., Inj. Ivermectin s.c. and Tonovita i.m. once and multimineral bolus once daily for 7 days. Repeat breeding cows received additional single shot i.m. injection of Enrofloxacin. All the anestrus and repeat breeder cows (100\%) under all four treatment protocols exhibited induced estrus between 48 and $72 \mathrm{hrs}$ from $\mathrm{PGF}_{2} \alpha$ injection. The conception rates obtained in anestrus cows at induced estrus (FTAI) and overall of three cycles post-treatment were 20.0 and $60.0 \%$ with Ov_synch; 20.0 and $50.0 \%$ with Ov_synch Plus; 40.0 and $80.0 \%$ with Double_synch, and 30.0 and $60.0 \%$ with Estradoublesynch protocol, respectively. The corresponding conception rates in repeat breeder cows were 30.0 and $70.0 \%$ with Ov_synch; 30.0 and 50.0\% with Ov_synch Plus; 40.0 and $80.0 \%$ with Double_synch, and 20.0 and $60.0 \%$ with Estradoublesynch protocol, respectively. All non-conceived repeat breeding cows under each protocol, except 1 in Ov_synch Plus protocol,
\end{abstract}

AR Prajapati, AJ Dhami( $\varangle)$, KK Hadiya, JA Patel and JP Prajapati Department of Animal Reproduction Gynaecology and Obstetrics College of Veterinary Science and Animal Husbandry

Anand Agricultural University, Anand-388 001, Gujarat, India

E-mail: ajdhami@aau.in, Mobile: +919898262498 continued cycling, while among 10 anestrus cows each treated with Ov_synch, Ov_synch Plus, Double_synch and Estradoublesynch protocol, 2, 2, 0 and 1 cows again turned out to be anestrus by 60 days post-induction/FTAI, respectively. Among the untreated control anestrus and repeat breeder cows (10 each), 2 and 3 cows conceived over a period of 90 days follow up giving overall conception rates of only 20.0 and $30.0 \%$, respectively, as against the overall fertility rate of 62.5 and $65.0 \%$ in treated anestrus and repeat breeder cows, respectively, over just mean 28-32 days of treatment, suggesting the economic utility of these protocols in handling the problem breeder cows under field conditions.

Keywords: Crossbred cows, Cyclic, Acyclic, Conception rate, Estrus synchronization

\section{Introduction}

Various hormonal preparations and protocols are being practised by the field veterinarians to treat postpartum anestrus and repeat breeding, the most prevalent reproductive problems, in dairy animals. But the results reported are inconsistent (Ghuman et al., 2009; Bhoraniya et al., 2012; Dhami et al., 2015) largely due to nutritional status, faulty management, ovarian changes, endocrine events and even uterine infection. Hormonal therapies have good therapeutic value to enhance reproductive efficacy in infertile animals only with good nutritional status (Chaudhari et al., 2012; Savalia et al., 2014). Further, the literature on recently coined Double_synch and Estradoublesynch protocols (Miramahmoudi et al., 2014) is meagre in infertile cattle. Hence, this study was planned to evaluate the comparative efficacy of Ov_synch, Ov_synch Plus, Double_synch and Estradoublesynch protocols in anestrus and repeat breeding crossbred cows of average body condition scores (BCS) in terms of estrus response and fertility enhancement under field conditions.

\section{Materials and methods}

The study was carried out in villages under the milk shed areas of AMUL, Anand and Panchamrut Dairy, Godhara, Gujarat from August, 2016 to February, 2017. Fifty postpartum ( $>90$ days) 
true anestrus (acyclic) and 50 classical repeat breeding (cyclic) crossbred cows of average BCS ( 2.5 to 3.0 on 5 point scale) were screened gynaeco-clinically for their reproductive status. Anestrus cows were confirmed by palpating small smooth inactive ovaries per rectum twice 10 days apart. Repeat breeders were confirmed on the basis of regular cyclicity and AI for more than 3 times without visible or palpable genital abnormality, yet failed to conceive. All these infertile animals were initially injected once with $100 \mathrm{mg}$ Ivermectin s.c. (Inj. Ivectin, $10 \mathrm{ml}$, Indian Immunologicals Ltd, Hyderabad), and injection inorganic phosphorus (Inj. Tonophosphan, MSD Animal Health, Pune) and multivitamins $\mathrm{AD}_{3} \mathrm{E}$ (Inj. Intavita- $\mathrm{H}$, Intas Pharma, Ahmedabad) $10 \mathrm{ml}$ each i.m., and were supplied with bolus Minotas (Intas Pharma) @ 1 bolus PO for 7 days. Repeat-breeder cows received additional single shot i.m. injection of Enrofloxacin (Inj. Flobac SA, $40 \mathrm{ml}$, Intas Pharma). They were randomly divided into 5 equal groups $(n=10$ each) and were subjected to following four estrus induction/synchronization protocols, keeping one group each as untreated control.

\section{Ov_synch and Ov_synch plus protocols}

Under Ov_synch protocol, 10 acyclic and 10 cyclic crossbred cows each were administered with i.m. Inj. of $20 \mu \mathrm{g}$ of $\mathrm{GnRH}$ analogue, i.e. Buserelin acetate (Receptal, $5 \mathrm{ml}$, MSD Animal Health) on day 0 , Inj. of $500 \mu \mathrm{g} \mathrm{PGF}_{2} \alpha$ analogue, i.e. Cloprostenol sodium (Estrumate, $2 \mathrm{ml}$, MSD Animal Health) on day 7, and second Inj. of $10 \mu \mathrm{g}$ of GnRH on day 9 , followed by FTAI twice at 0 and 24 hrs later. In Ov_synch Plus protocol, 10 acyclic and 10 cyclic cows each received an additional i/m Inj. of PMSG 500 IU (Folligon, MSD Animal Health) 2 days before the actual Ov_synch protocol.

\section{Double_synch and Estradoublesynch protocols}

Under Double_synch protocol, 10 acyclic and 10 cyclic cows were administered with i.m. Inj. of $500 \mu \mathrm{g} \mathrm{PGF} \mathrm{PG}_{2} \alpha$ analogue, i.e. Cloprostenol sodium (Estrumate, $2 \mathrm{ml}$ ) on day 0 , Inj. of $20 \mu \mathrm{g}$ of $\mathrm{GnRH}$ analogue, i.e. Buserelin acetate (Receptal, $5 \mathrm{ml}$ ), on day 2, $500 \mu \mathrm{g} \mathrm{PGF}_{2} \alpha$ analogue (Estrumate, $2 \mathrm{ml}$ ) on day 9 and second Inj. of $10 \mu \mathrm{g}$ of $\mathrm{GnRH}$ analogue on day 11, followed by FTAI twice at 16 and $24 \mathrm{hrs}$ later, while in Estradoublesynch protocol, 10 acyclic and 10 cyclic cows received an Inj. of estradiol benzoate $1 \mathrm{mg}$ (Sigma, USA) on day 10, in place of second GnRH injection on day 11 in Double_synch with FTAI twice at 48 and $60 \mathrm{hrs}$ post-estradiol injection.

\section{Control groups}

Ten cyclic repeat breeder and 10 acyclic anestrus cows each given pre-synchronization treatment as above, but without any hormonal intervention, and followed for spontaneous estrus and insemination, served as untreated controls.
Visual heat detection for half an hour both in the morning and evening and frozen semen inseminations were practiced as per the protocols throughout the study period. Animals inseminated at induced/spontaneous estrus, if not settled, were followed for 2 more cycles and in non-return cases pregnancy was confirmed per-rectum 60 days post-AI. The observations on estrus responses and conception rates were recorded and compared statistically between different groups by using Chi-square test (Snedecor and Cochran, 1986).

\section{Results and discussion}

The results obtained on estrus induction responses, estrus induction intervals and conception rates in acyclic and cyclic crossbred cows under different synchronization protocols and control groups are presented in Table 1.

\section{Estrus induction response and induction intervals in acyclic/ anestrus cows}

The estrus induction response was $100 \%$ in acyclic cows under all four protocols with good exhibition of estrus signs. The mean estrus induction intervals from $7^{\text {th }} / 9^{\text {th }}$ day $\mathrm{PGF}_{2} \alpha$ injection were $70.1 \pm 1.81,65.6 \pm 1.02,66.1 \pm 0.76$ and $63.4 \pm 2.06 \mathrm{hrs}$ in Ov_synch, Ov_synch Plus, Double_synch, Estradoublesynch protocols, respectively. However in acyclic control group, only two cows $(20.0 \%)$ showed spontaneous estrus after 32 and 56 days from start of supportive therapy (Table 1).

Higher estrus induction response (100\%) with Ov_synch protocol in acyclic cows as observed in the present study has also been reported by Virmani et al. (2013), Buhecha et al. (2015) and Ahmed et al. (2016). However, relatively lower induction response of 20.0 to $67.0 \%$ has been reported by others (Mahour et al., 2012; Naikoo et al. 2016). The present $100 \%$ estrus induction rate in acyclic cows under Ov_synch Plus protocol was also in line with that reported by Virmani et al. (2013) and Kumar et al. (2016). However, the estrus induction rates of $70.0 \%$ in Double_synch and $80.0 \%$ in Estradoublesynch reported by Parida et al. (2015) in anestrus buffaloes were comparatively lower $\%$ than the present $100 \%$ response rate in crossbred cattle under both the protocols. Miramahmoudi and Prakash (2012) reported $90 \%$ induction of estrus acyclic buffaloes using Double_synch protocol.

The mean estrus induction interval of $70.1 \pm 1.81 \mathrm{hrs}$ in Ov_synch protocol in the present study is comparable with the findings of Patel et al. (2013), Buhecha et al. (2015) and Borkhatariya et al. (2016) using same protocol on anestrus crossbred cows. No published work could be found to compare present estrus induction intervals following Ov_synch Plus, Double_synch and Estradoublesynch protocols in acyclic bovines. However, in our study all these protocols were at par with other standard protocols 
as far as estrus induction rates and estrus induction intervals were concerned.

\section{Conception rates with different estrus induction protocols in acyclic cows}

The conception rates obtained at induced estrus in acyclic cows under Ov_synch, Ov_synch Plus, Double_synch, Estradoublesynch protocols were 20,20,40 and 30\%, respectively, and the corresponding three cycles' overall conception rates achieved were $60,50,80$ and $60 \%$. These results were obtained in a period of $25.7 \pm 4.57,29.0 \pm 7.21,24.3 \pm 6.23$ and $29.0 \pm 9.66$ days from the day of start of treatment in respective groups (Table 1). In all, 25 cows conceived out of 40 anestrus cows treated with different protocols giving overall success rate of $62.5 \%$ over just 10-50 (mean 28-32) days of treatment and follow up period. In contrast, among untreated acyclic control group, only two cows exhibited spontaneous estrus and conceived over a 90-days follow up period giving overall conception rate of $20 \%$ only. The service period in the control group was $158.1 \pm 12.36$ days. The results proved beneficial role of inducing estrus in anestrus animals with the referred protocols, which significantly enhanced pregnancy rate and curtailed calving interval making them economically productive compared to untreated ones.

In the present study, the first service (FTAI) conception rates obtained with Ov_synch and Double_synch protocols were in accordance with Abubaker et al. (2013), who reported the values as 42.9 and $28.6 \%$, respectively, in crossbred cows. Virmani et al. (2013) reported $20.0 \%$ conception rate at FTAI with Ov_synch Plus protocol in postpartum anestrus Sahiwal cows. However, Raposo (2013) and Roodbari et al. (2015) found vary low conception rates of only 13.3 and $20.0 \%$ and 26.2 and $18.7 \%$, respectively, with Estradoublesynch and Double_synch protocols in HF cows. While Parida et al. (2015) reported 57.7 and $62.5 \%$ conception rates, respectively, with the same protocols in anestrus buffaloes. Similarly, the conception rates of 55-58\% reported by Mirmahmoudi and Prakash (2012), Mirmahmoudi et al. (2014) and Dhindsa et al. (2016) in acyclic buffaloes were comparatively higher than the present results with Double_synch protocol. Sharavanan et al. (2016) found much higher first service conception rates of 57.1 and $59.5 \%$ in anestrus cows using Ov_synch and Estradoublesynch protocols, respectively. Using Ov_synch protocol, Buhecha et al. (2015) and Tenhagen et al. (2004) recorded first service conception rates of 41.7 and $31.6 \%$, and overall pregnancy rates of 58.3 and $75.5 \%$ in anestrus cows, while Kumar et al. (2016) found first service and overall conception rates of 56.0 and $75.0 \%$ in anestrus buffaloes using Ov_synch plus protocol.

The present overall three cycles' pregnancy rate obtained in acyclic cows under Double_synch protocol was the highest (80 $\%$ ) followed by that with Ov_synch (60\%), Estradoublesynch $(60 \%)$ and Ov_synch Plus $(50 \%)$. This overall conception rate of
$80.0 \%$ achieved in acyclic cows under Double_synch protocol corroborated well with the finding of Ozturk et al. (2010) as $72.8 \%$. However, Naikoo et al. (2016) recorded only 33.3\% overall conception rate using Ov_synch protocol in anestrus Kankrej cows. Sahoo et al. (2017) reported lower conception rates of 60.0 and 55.0\% with Estradoublesynch and Double_synch protocols. The present overall conception rates obtained in acyclic cows under Ov_synch and Double_synch protocols were in accordance with Abubaker et al. (2013), who also reported $71.4 \%$ overall conception rates with both these protocols. Very limited research work could be found in the literature on use of Ov_synch Plus, Double_synch and Estradoublesynch protocols in bovines under Indian subcontinent.

\section{Estrus synchronization responses and induction intervals in repeat breeder cows}

In cyclic repeat breeder cows under Ov_synch, Ov_synch Plus, Double_synch and Estradoublesynch protocols, the estrus synchronization response was $100 \%$ each with good exhibitory estrus signs. The mean estrus induction intervals from $\mathrm{PGF}_{2} \alpha$ injection were $62.1 \pm 2.26,64.6 \pm 2.02,65.1 \pm 1.25$ and $69.5 \pm 1.16 \mathrm{hrs}$, respectively (Table 1).

Similar 100\% estrus synchronization response with Ov_synch was also reported by Vijayrajan et al. (2009) and Chaudhary et al. (2012) in cyclic cows. Estrus synchronization rate of $100 \%$ achieved in repeat breeder cows with Double_synch and Estradoublesynch protocols was in harmony with the earlier results of 83.3 to $100 \%$ by Miramahmoudi et al. (2014) in cyclic buffaloes, wherein estrus was induced within 72-96 hrs of PG injection.

Ahmed et al. (2016) and Vijayrajan et al. (2009) reported shorter estrus induction intervals of $48.8 \pm 0.71$ and $52.1 \pm 2.39 \mathrm{hrs}$ with Ov_synch protocol as compared to $62.1 \pm 2.26 \mathrm{hrs}$ found in present cyclic cows. However, Patel et al. (2013) reported estrus induction response within $82.7 \pm 4.22 \mathrm{hrs}$ with $\mathrm{Ov}$ _synch protocol which is slightly longer than the present findings.

\section{Conception rates with different synchronization protocols in repeat breeder cows}

The conception rates obtained at induced estrus in cyclic repeat breeder cows under Ov_synch, Ov_synch Plus, Double_synch and Estradoublesynch protocols were found to be 30, 30, 40 and $20 \%$, respectively, and the corresponding overall three cycles' conception rates were $70,50,80$ and $60 \%$. These results were obtained within a period of $27.0 \pm 6.73,25.0 \pm 7.88,23.6 \pm 3.66$ and $27.2 \pm 5.56$ days from the day of start of treatment in respective groups (Table 1). In all, 26 cows conceived out of 40 repeat breeder cows treated with different protocols, giving overall success rate of $65.0 \%$ over just $10-50$ days of treatment and follow up period. The rests all non-conceived treated cows continued to remain cycling, except 1 cow in Ov_synch Plus protocol, which 


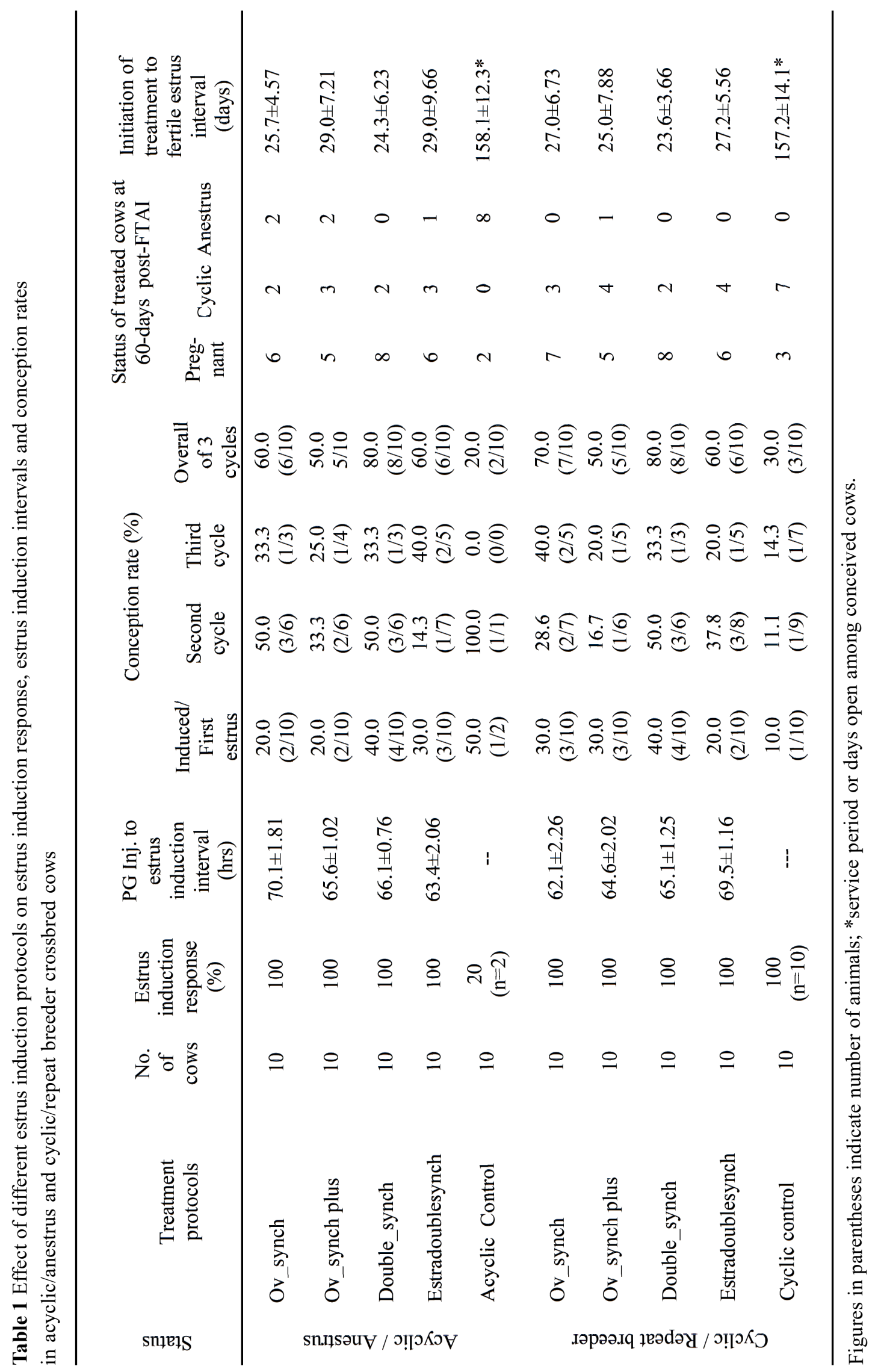


became anestrus. In contrast, among untreated repeat breeder control group, all the cows exhibited spontaneous estrus regularly with one each conceived at first, second and third cycle over a 90-days follow up period giving overall conception rate of $30.0 \%$ only. The service period in the control group was $157.2 \pm 14.10$ days, which was nearly 50 to 55 days longer than in repeat breeder cows under various treatment protocols (Table 1). These results proved advantage of synchronizing estrus in repeat breeding animals also with the referred protocols as compared to those left untreated.

The present conception rate of $30.0 \%$ as obtained at FTAI in cyclic repeat breeding cows under Ov_synch protocol was similar to Prajapati et al. (2015), but their overall 3 cycles conception rate was only $55.0 \%$ against $70.0 \%$ in present study, while Vijayrajan et al. (2009), Chaudhary et al. (2012) and Parmar et al. (2015) recorded relatively higher conception of $50.00 \%$ each at FTAI, but their overall three cycles' conception rates $(60,75$ and $70 \%$ ) were in close accordance with present finding. Ahmed et al. (2016) also found $50.0 \%$ conception at FTAI following Ov_synch protocol in repeat breeding crossbred cows. Patel et al. (2013) documented the first service and overall conception rates of 3 cycles as 40 and $80 \%$ with Ov_synch protocol in repeat breeding crossbred cows that were comparatively higher than the present ones. However, no report on use of Ov_synch plus protocol in repeat breeder bovine could be found in the literature. This protocol in fact did not prove beneficial over simple Ov_synch protocol and had relatively poor overall conception rate in spite of using addition PMSG injection in our study.

In the present study, the first service conception rates of 40.0 and $20.0 \%$ found in repeat breeder cows with Double_synch and Estradoublesynch protocols, respectively, compared with report of Kumar et al. (2016) using Double_synch during summer and winter seasons in buffaloes (40 and $48 \%$ ), but was lower than $60-62 \%$ reported with both these protocols by Mirmahmoudi and Prakash (2012) and Mirmahmoudi et al. (2014) in cycling buffaloes and by Sahoo et al. (2017) in cyclic crossbred cows (60 and $55 \%$ ). However, no report could be located on use of Double_synch and Estradoublesynch protocol in cyclic / repeat breeder bovine documenting cumulative results of two or more cycles to support the present finding, which is up to 80 and $60 \%$ in our study. Here also replacing second GnRH injection of Double_synch with estradiol benzoate did not prove advantageous in terms of first service and even overall conception rates in cyclic repeat breeder cows, and the results were comparative better with Double_synch protocol itself.

\section{Conclusions}

Based on the findings of our present study, it was concluded that Double_synch and Ov_synch are the better protocols for induction of ovulatory estrus and improving conception rates in both anestrus and repeat breeding crossbred cattle. However, further studies on large number of animals are needed to be undertaken on Estradoublesynch and Ov_synch Plus protocols to prove their utility over Double_synch and Ov_synch protocols.

\section{Acknowledgements}

We thank Dean of the faculty for the facilities provide, dairy farmers for kind cooperation, and ICAR for sanctioning project "AICRP on Nutritional \& Physiological Interventions for Enhancing Reproductive Performance in Dairy Animals" to the College with Dr AJ Dhami as Principal Investigator.

\section{References}

Abubaker PS, Kurien MO, Ghosh KN, Simon S, Anil KS, Becha BB (2013) Ovulation synchronisation for improving fertility in postpartum cows. J Vet Anim Sci 44: 42-45

Ahmed N, Kathiresan D, Ahmed FA, Lalrintluanga K, Mayengbam P, Gali JM (2016) Pattern of induced estrus and conception rate following Ovsynch and Ovsynch based gonadotropin-releasing hormone treatments initiated on day 6 of estrous cycle in repeat breeding crossbred cows. Vet. World 9(1): 342-345

Bhoraniya HL, Dhami AJ, Naikoo M, Parmar BC, Sarvaiya NP (2012) Effect of oestrus synchronization protocols on plasma progesterone profile and fertility in postpartum anoestrus Kankrej cows. Trop Anim Health Prod 44(6): 1191-1197

Borakhatariya DN, Panchal MT, Dhami AJ, Hadiya KK, Kalasariya RM (2016) Efficacy of estrus synchronization protocols during summer and winter seasons together with biochemical and minerals profile in anestrus crossbred cows. Indian J Vet Sci Biotech 13(1): 9-16

Buhecha KV, Dhami AJ, Hadiya KK, Patel MD, Parmar SC, Killedar A (2015) Influence of different estrus synchronization protocols on fertility and plasma progesterone in anoestrus crossbred cows. Indian J Anim Reprod 36(2): 1-5

Chaudhary AK, Panchal MT, Dhami AJ, Shah RG (2012) Effect of Ovsynch and one shot $\mathrm{PGF}_{2} \alpha$ protocols on estrus synchronization, plasma progesterone and conception rate in cyclic crossbred cows under field condition Proc. National Symposium on Addressing Animal Reproductive Stresses through Biotechnological Tools and XXVII Annual Convention of ISSAR, Nov. 21-23, Pantnagar, UP, p. 71

Dhami AJ, Nakrani BB, Hadiya KK, Patel JA, Shah RG (2015) Comparative efficacy of different estrus synchronization protocols on estrus induction response, fertility and plasma progesterone and biochemical profile in crossbred anestrus cows. Vet World 8(11): $1310-1316$

Dhindsa SS, Honparkhe M, Grewal RS, Brar PS (2016) Fertility enhancement through Doublesynch protocol in buffalo during summer season. Indian Vet J 93(10): 17-19

Ghuman SPS, Singh J, Honparke M, Dadarwal D (2009) Induction of ovulatory oestrus using Ovsynch protocol and subsequent fertility in true anestrous buffalo heifers. Indian J Anim Reprod 30(2): 1-5

Kumar L, Phogat JB, Pandey AK, Phulia SK, Kumar S, Dalal J (2016) Estrus induction and fertility response following different treatment protocols in Murrah buffaloes under field conditions. Vet World 9(12): 1466-1470

Mahour SS, Nema SP, Shukla SP, Mehta HK, Gupta VK (2012) Efficacy of $\mathrm{PGF}_{2} \alpha, \mathrm{GnRH}$ and Ovsynch protocol in postpartum anoestrus crossbred cows. Indian J Field Vets 8(1): 65-68 
Mirmahmoudi R, Prakash BS (2012) The endocrine changes, the timing of ovulation and the efficacy of the Doublesynch protocol in the Murrah buffalo (Bubalus bubalis). General Comp Endocrinol 177: 153-159

Mirmahmoudi R, Souri M, Prakash BS (2014) Endocrine changes, timing of ovulation, ovarian follicular growth and efficacy of a novel protocol (Estradoublesynch) for synchronization of ovulation and timed artificial insemination in Murrah buffaloes (Bubalus bubalis). Theriogenology 81: 237-242

Naikoo M, Dhami AJ, Ramakrishnan A (2016) Effect of estrus synchronization on plasma progesterone profile and fertility response in postpartum suckled anestrus Kankrej cows. Indian J Anim Res 50(4): 460-465

Ozturk OA, Cirit U, Baran A, Ak K (2010) Is Doublesynch protocol a new alternative for timed artificial insemination in anestrous dairy cows. Theriogenology 73: 568-576

Parida PK, Mishra PC, Mohanty DN, Swain RK, Barik AK, Das S (2015) Successful use of different synch protocols for estrus induction in buffaloes. Proc. XXXI Annual Convention of ISSAR, Dec., 3-5, Veterinary College, Hebbal, Bengaluru, p. 28

Parmar CP, Patel DM, Hadiya KK, Dhami AJ, Buhecha KV, Sarvaiya NP (2015) Fertility and plasma progesterone profile in repeat breeding cows and buffaloes in Ovsynch and mid-cycle $\mathrm{PGF}_{2} \alpha$ treatment protocols. Indian J Anim Reprod 36(2): 29-32

Patel KR, Dhami AJ, Hadiya KK, Savalia KK, Sarvaiya NP (2013) Effect of CIDR and Ovsynch protocols on estrus response, fertility and plasma progesterone and biochemical profile in true anoestrus crossbred cows. Indian J Anim Prod Mgmt 29(3-4): 50-58

Prajapati KA, Sharma PK, Choudhry MK (2015) Management of repeat breeding under field condition using Ovsynch protocol in crossbred cows. J Krishi Vigyan 4(1): 60-62
Raposo MA (2013) Comparative study of two ovulation synchronization protocols in Holstein Frisian cows: Ovsynch and Doublesynch. Masters Dissertation. University of Lisbon, Faculty of Veterinary Medicine, Lisbon,_Portugal, p. 1-2.

Roodbari AR, Dirandeh E, Colazo MG (2015) A new ovulation synchronization protocol (Estradoublesynch) improves fertility in heat-stressed lactating Holstein cows. $3^{\text {rd }}$ Int. Congr. Large Animal Practitioners, Tehran, Iran, Feb 2015.

Sahoo JK, Das SK, Sethy K, Mishra SK, Swain RK, Mishra PC, Sahoo SP (2017) Comparative evaluation of hormonal protocol on the performance of crossbred cattle. Trop Anim Health Prod 49: 259263

Savalia KK, Dhami AJ, Hadiya KK, Patel KR, Sarvaiya NP (2014) Influence of controlled breeding techniques on fertility and plasma progesterone, protein and cholesterol profile in true anoestrus and repeat breeding buffaloes. Vet World 7: 727-732

Shravanan V, Kulasekar K, Krishnakumar K, Venkantaramanna S (2016) Synchronization of ovulation using Ovsynch and Estradoublesynch protocols in crossbred cattle. Proc. $32^{\text {nd }}$ Annual Convention of ISSAR and National Seminar on Animal Fertility and Fecundity at Crossroads. Dec. 6-8, Tirupati, India, p. 29

Snedecor GW, Cochran WG (1986) Statistical Methods. $8^{\text {th }}$ edn. Iowa State University Press, Ames, Iowa, USA

Tenhagen AB, Surholt Miriam R, Wittke M, Vogel C, Drillich M, Heuwieser W (2004) Use of Ovsynch in dairy herds differences between primiparous and multiparous cows. Anim Reprod Sci 81: 1-11

Vijayrajan A, Chandrahasan C, Ezakial Napoleon R (2009) Synchronization of ovulation in repeat breeding crossbred cows. Indian J Field Vets 5: 57-58

Virmani M, Malik RK, Dalal DS, Singh P, Vikash (2013) Comparing efficacy of different hormonal protocols for induction of cyclicity in postpartum anestrus Sahiwal cows. Haryana Vet 52: 121-123 